ASEAN Journal of Science and
Engineering Education

\title{
Integrated Project as Innovative Assessment to Enhance Learning Experience in Thermodynamics Class
}

\author{
Nonni Soraya Sambudi*, Raihan Mahirah Ramli \\ Department of Chemical Engineering, Universiti Teknologi PETRONAS, Seri Iskandar, 32610 Perak, Malaysia \\ *Correspondence: E-mail: soraya.sambudi@utp.edu.my
}

\section{A B S TR A C T S}

An integrated project is introduced to students to relate the concepts and equations taught between courses in the same semester. It also helps students in managing allocated time for assessments and collaborating among them, which eventually enhances their learning experience, especially for thermodynamics courses. In this case, the integrated project was done by relating two courses: Chemical Engineering Thermodynamics 2 and Separation Process 1 for Year 2 students. The methanol production plant was chosen as a model case, where students need to simulate the vapor/liquid equilibrium in the purification unit using HYSYS simulation software. Overall, students show highly positive sentiments upon the projects, in which more than $90 \%$ of them think that the project helps them to understand the coursework materials and prepare for other assessments. The majority of students want to experience the same type of project in the future, and it helps to save their time rather than working on separate projects. The project also exposes the students to set skills related to technical competence and soft skills that could build their characters.

\author{
ARTICLE INFO \\ Article History: \\ Submitted/Received 27 Oct 2021 \\ First revised 26 Nov 2021 \\ Accepted 28 Nov 2021 \\ First available online 30 Nov 2021 \\ Publication date 01 Dec 2021 \\ Keyword: \\ Integrated project, \\ Project-based learning, \\ Simulation, \\ Thermodynamics.
}




\section{INTRODUCTION}

Thermodynamics teaching is closely related to the energy transfer, work, temperature, and their relation with the process in a system. The principles of thermodynamics are related to many energy systems such as refrigeration, power plants, and also chemical processes (Mulop et al., 2012). For chemical engineering students, thermodynamics is a core subject and quite challenging to comprehend, as stated in previous studies, which can lead to the misconception (Baran \& Sozbilir, 2018; Mulop et al., 2012). Since outcome-based education is adopted, the shifting of the teaching and learning process is strongly going towards studentcentered active learning (Ballesteros et al., 2019).

Innovative assessment can be introduced as a method to improve the learning experience of students, which eventually improves their understanding of the subject, especially through project-based learning. Project-based learning attracts students to use their skills by organizing them in small groups with minimal guidance and contextualizing real problems (Baran \& Sozbilir, 2018). On a smaller scale than project-based learning, the integrated project has been applied to improve the participation of students in the learning process and develop collaborative work among the students, in helping them to face diverse environments (Trisdiono et al., 2019). Besides, soft skills such as communication, critical thinking, and selfconfidence of students have been found to improve as well (Sidik \& Masek, 2021; Trisdiono et al., 2019).

Throughout their study, many times students find it difficult to relate between the taught courses. By introducing integrated projects between Thermodynamics and Separation Process courses, students are expected to relate to the concepts and the equations between these courses in a chemical process, so they can see the knowledge as a whole. The design of process flow, mass balance calculation, and vapor-liquid equilibrium graphs construction from instruments designated to purify the product are addressed in this integrated project.

Through the integration of the integrated project in teaching and learning, students can visualize and approach the taught concepts in the class by using a real case study. During their discussion in a team, students can brainstorm ideas, negotiate on the possible solutions, and some can lead their peers (Antequera \& Herrero, 2012; Ballesteros et al., 2019). Hence, they can deepen their understanding through the activities related to the project (Ballesteros et al., 2019). Additionally, students also need to integrate the simulation of constructing the vapor-liquid equilibrium graphs by using HYSYS simulation software. During the limited number of weeks (12 weeks) designated for teaching in a semester in Universiti Teknologi PETRONAS, the integrated project can be a beneficial tool to help the students in managing their time for assessments between all different classes that they take (Ballesteros et al., 2019). The students' feedback and satisfaction upon the integrated project are assessed at the end of project implementation.

\section{METHODS}

The integrated project combines the projects for Separation Process 1 and Chemical Engineering Thermodynamics 2 courses for the 2nd-year students in September 2020 semester. A total of 175 students participate and are organized into 41 groups, in which each group consists of $4-5$ students. The integrated project contributes to $15 \%$ of the overall coursework mark.

The methanol production process was used as the case study, in which students need to design the process according to the assigned purity of the product. The assigned tasks for students are listed as follow:

DOI: $\underline{\text { http://dx.doi.org/10.17509/xxxx.Xxxx }}$ p- ISSN 2775-6793 e- ISSN 2775-6815 
(i) Provide an introduction to methanol.

(ii) Propose suitable plant capacity with business/market analysis justification.

(iii) Provide the selection of instruments for the methanol production process.

(iv) Draw the process flow diagram of methanol production from natural gases by using appropriate software and describe the process flow in detail.

(v) Use HYSYS software to generate the vapor/liquid equilibrium graph, construct the phase envelope, and predict the mole fraction of vapor over liquid, vapor composition, and liquid composition using flash calculation.

(vi) Design the distillation column for the methanol purification unit.

(vii) Submit a final report and provide 10 minutes or recorded video presentation.

The duration of integrated project completion is 7 weeks, and the processes of formulating the project, announcement, and submission are shown in Figure 1. To implement the simulation part in the project and improve the experience of students upon the software, students were subjected to compulsory lab sessions to learn the operation of HYSYS software. At the end of the project, students need to fill in the peer-review and questionnaires to record their feedback for this project.

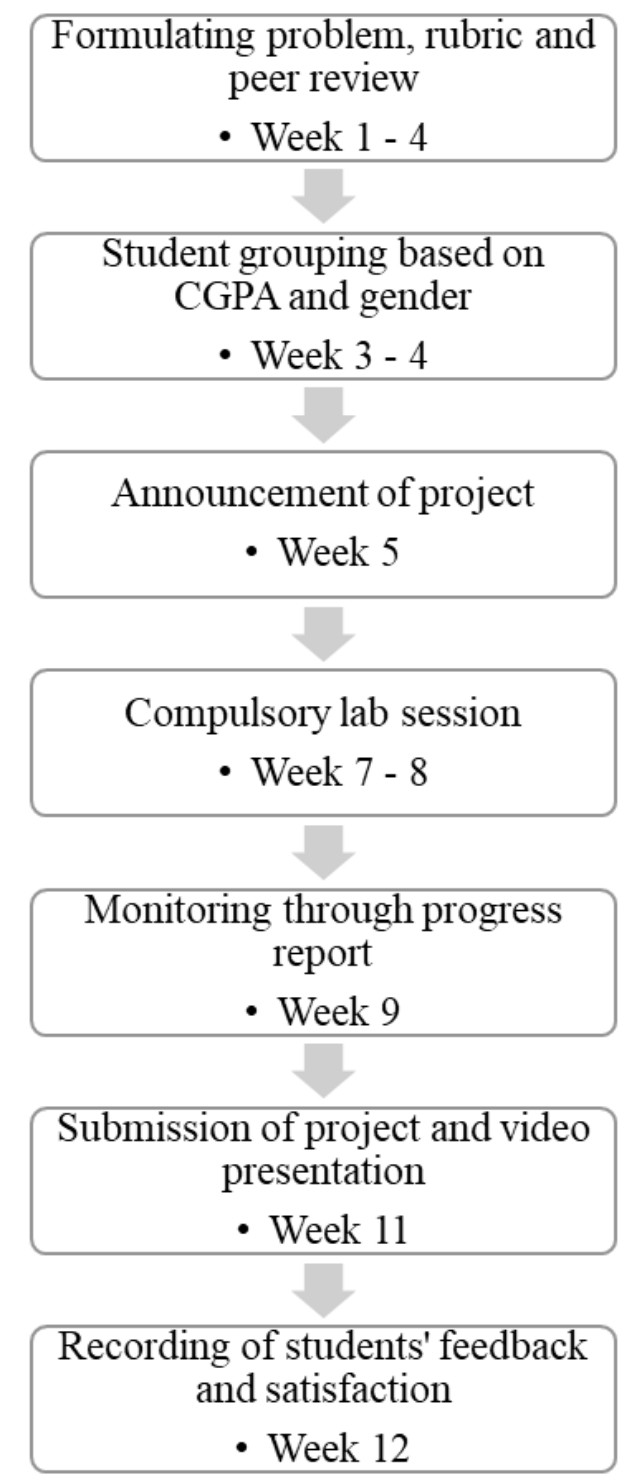

Figure 1. Flow of integrated project implementation. 


\section{RESULTS AND DISCUSSION}

The examples of solutions provided by students are shown in Figure $\mathbf{2}$ for the process flow diagram and Figure $\mathbf{3}$ for the HYSYS simulation results. Hence, the project introduces students to the drawing of the simple process flow diagram and conducting simulation related to the purification of methanol. These experiences are expected to equip them with a preliminary knowledge of chemical processes, before exploring it in depth during the capstone project in Year 4. Additionally, the introduction of the process flow diagram and HYSYS provide a framework to design problems for this integrated project, and students in Year 2 have enough time to gain moderate chemical engineering maturity to work on this project.

Based on the feedback provided by students, around $99.3 \%$ of students think that the project helps them to understand the coursework materials (Figure 4a), and around $93.6 \%$ of overall students think that the project helps them to prepare for a test or extended assignments (Figure $\mathbf{4 b}$ ), which is a replacement of ordinary final exam in the form of openended questions based exam. Hence, from these results, students think very positively about the project, especially in improving their understanding of thermodynamics concepts and applications. The project covers the vapor/liquid equilibrium of binary mixture and calculation related to it by involving HYSYS as a simulation tool. HYSYS itself has been widely used to explore the simulation of thermodynamics concepts related to ideal and non-ideal mixtures (Lopez-Zamora et al., 2021). Through this project, students can relate the concepts taught in class and HYSYS as simulation software can be used to produce the graphs related to vapor/liquid equilibrium variables such as the composition of liquid and vapor at different temperatures and pressures, as well as to perform the necessary calculation (Figure 3 ).

They emphasize the importance of teamwork and collaboration to provide solutions for this project is supported by $100 \%$ of students (Figure 5 a). While $37.1 \%$ of students strongly agree, $59.3 \%$ agree and only $3.6 \%$ do not agree that the project saves more time compared to a separate project (Figure $\mathbf{5 b}$ ). Hence, the project helps students to manage their time during the learning process in that semester. As stated in previous studies, working in a team for a project provides an opportunity to collaborate, discuss, share the knowledge and ideas that were integrated to provide solutions for the project (Ballesteros et al., 2019; Trisdiono et al., 2019). Hence, this positive experience will motivate them to work in a team in the future. This sentiment is supported by $80 \%$ of students that want to see this type of integrated project in the future. While $20 \%$ is still reluctant, which can be due to lack of freedom in choosing team members, since all groups are pre-assigned, and limited-time provided to complete the project.

The importance of teamwork is again emphasized in skills that students learned during the completion of the project (Figure 6). Students were asked to write down what skills that they have learned, and the collected answers were organized to show around six major sets of skills that appear on their answers: simulation software operation, drawing of process flow diagram, calculation technique, communication skill during working in a team, analysis of information, and preparing a good presentation. Around 3 sets of skills related to technical competencies, which are simulation software operation, drawing of process flow diagram, and calculation technique, with around $75.7 ; 50.0$; and $37.9 \%$ students, respectively, think that they acquire the skills. On the other hand, other 3 sets of skills related to soft skills, which are communication skills during working in a team, analysis of information, and preparing the good presentation, with around 23.6 ; 46.4 ; and $22.1 \%$ students, respectively, think that they were exposed to the skills. Therefore, the project can address both technical and soft skills for students' competence, which can help them to mature intellectually and socially.

DOI: http://dx.doi.org/10.17509/xxxx.xxxx p- ISSN 2775-6793 e- ISSN 2775-6815 


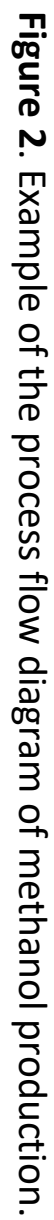

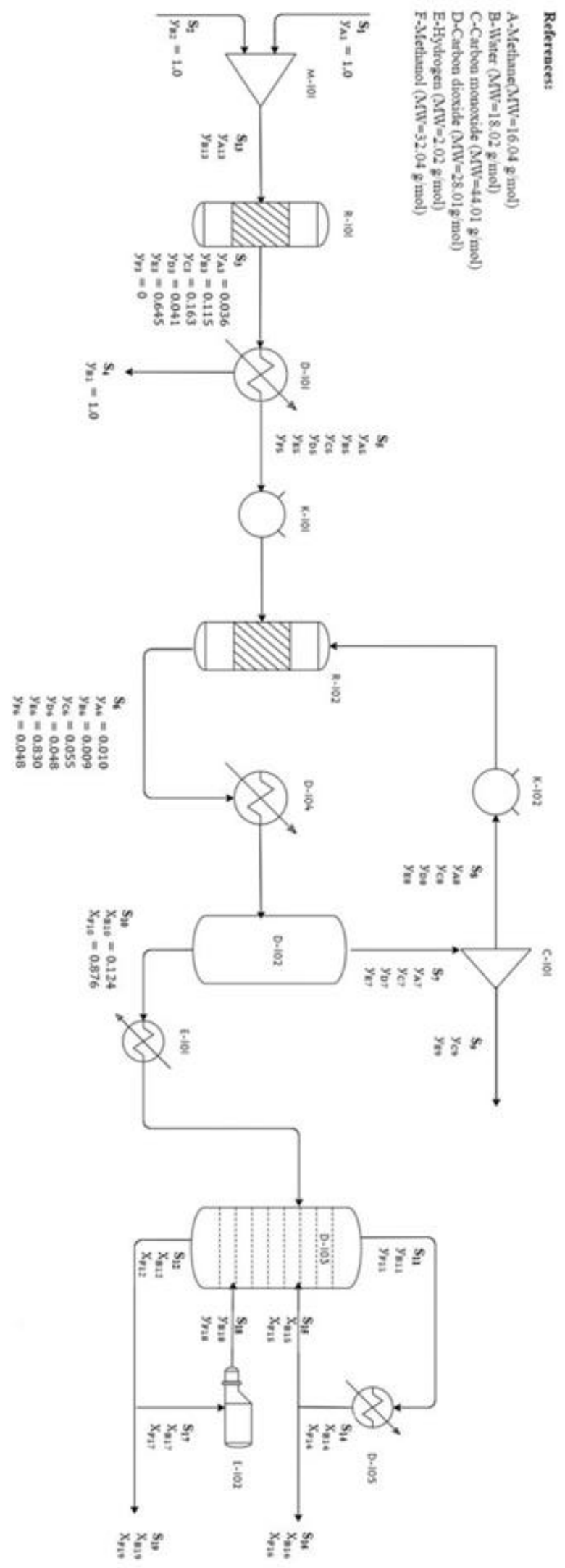

DOI: http://dx.doi.org/10.17509/xxxx.xxxx

p- ISSN 2775-6793 e- ISSN 2775-6815 


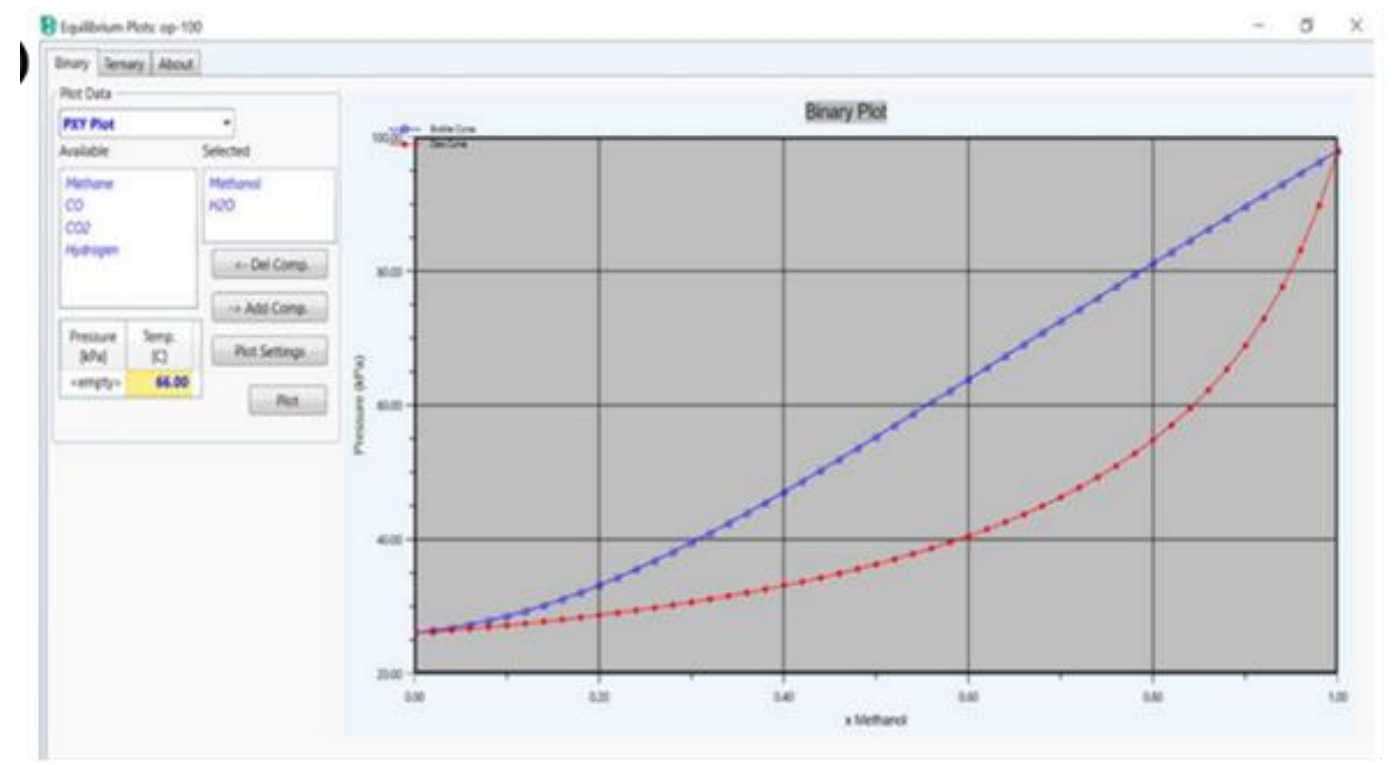

(a)

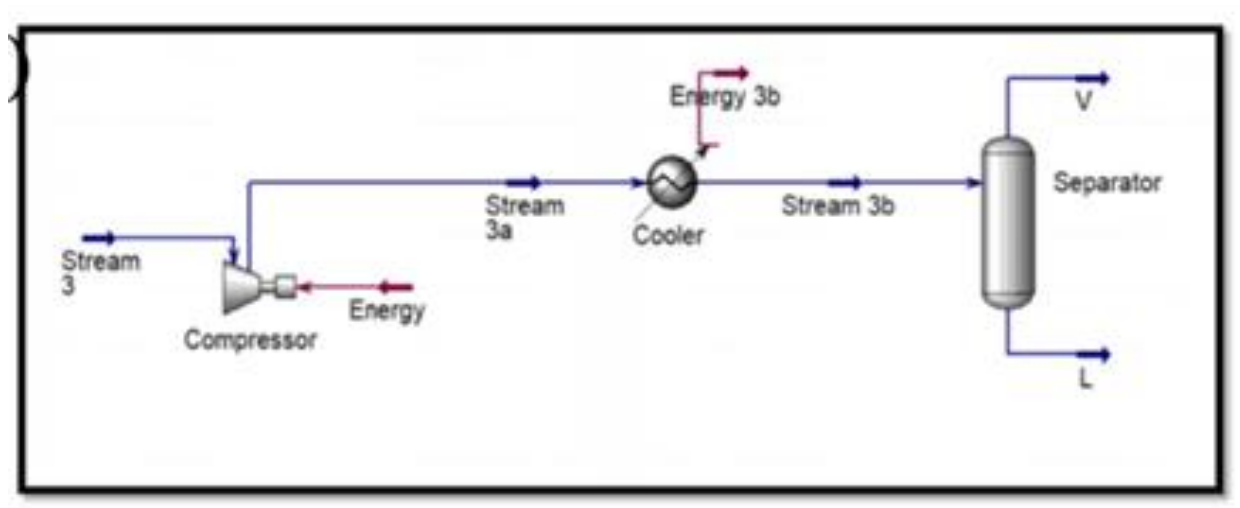

Simulation of the streams

\begin{tabular}{|c|c|c|}
\hline Streen Name & Stream 3 & Vespoue Phane \\
\hline Vopour / Thrise Fucsion & 1.0000 & 1.0000 \\
\hline iemperature i9 & $\$ 00.0$ & 8000 \\
\hline hessure fow & 1000 & 1000 \\
\hline Moler Fow Ragmole/ty & $1.862 e+004$ & $1.862 e+004$ \\
\hline Mass flow feghl & $1.921 e+005$ & $19210 \cdot 005$ \\
\hline Sad ldew tiq Vol flow In 3 Ay & 568.1 & 56a.1 \\
\hline Mole Enthalpy Re/kgmole! & -39540.004 & $-3954 \mathrm{e} \cdot 004$ \\
\hline 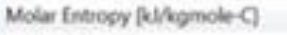 & 169.6 & 1696 \\
\hline Heat Flow Ha/s & $+7.361+0.006$ & $.7369+006$ \\
\hline Lia Vol flow esed Cond ln3N & $4396 e \cdot 005$ & $4.3986 \cdot 005$ \\
\hline Nidd Packenge & Anis-? & \\
\hline Untity lype & & \\
\hline
\end{tabular}

(b)

Figure 3. Examples of HYSYS simulation for a) vapor/liquid equilibrium graph, and b) flash calculation. 


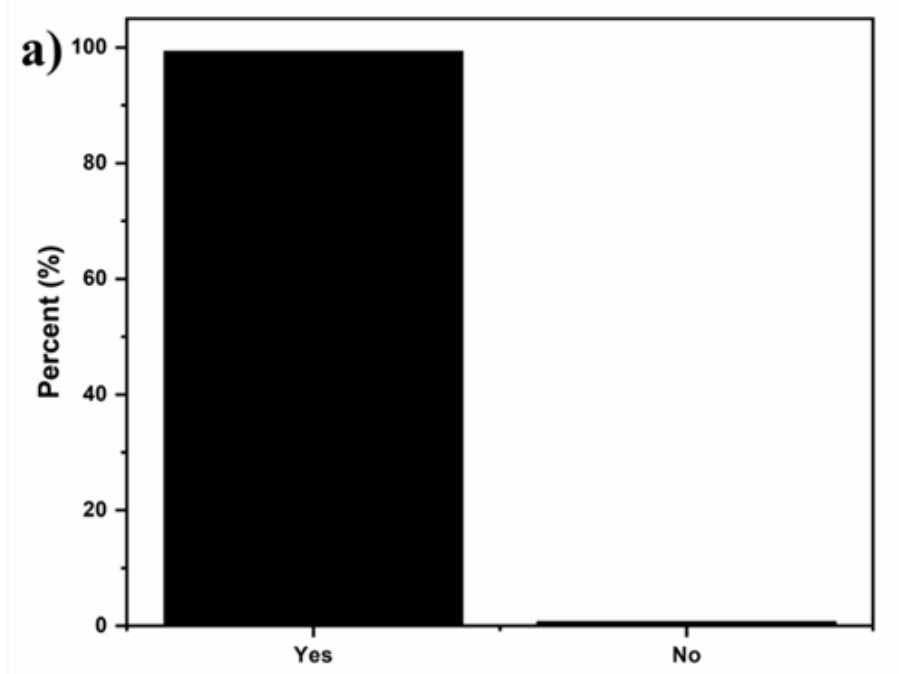

Does this project help to understand the coursework materials?

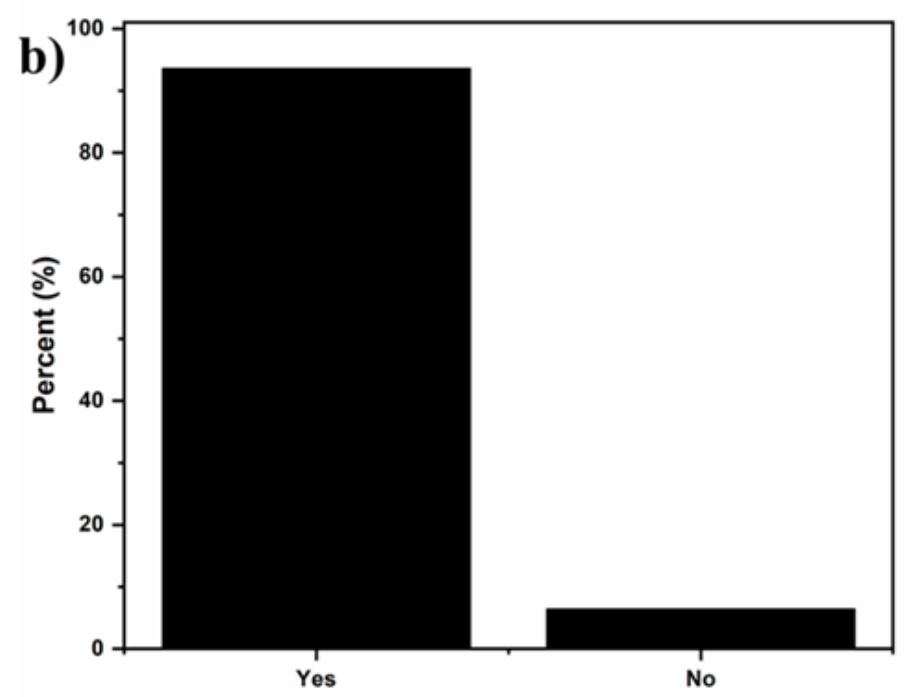

Does this project help to prepare for Test/Extended Assignment?

Figure 4. Feedback of students on whether the project helps to a) understand the coursework materials, and b) prepare for test/extended assignment. 


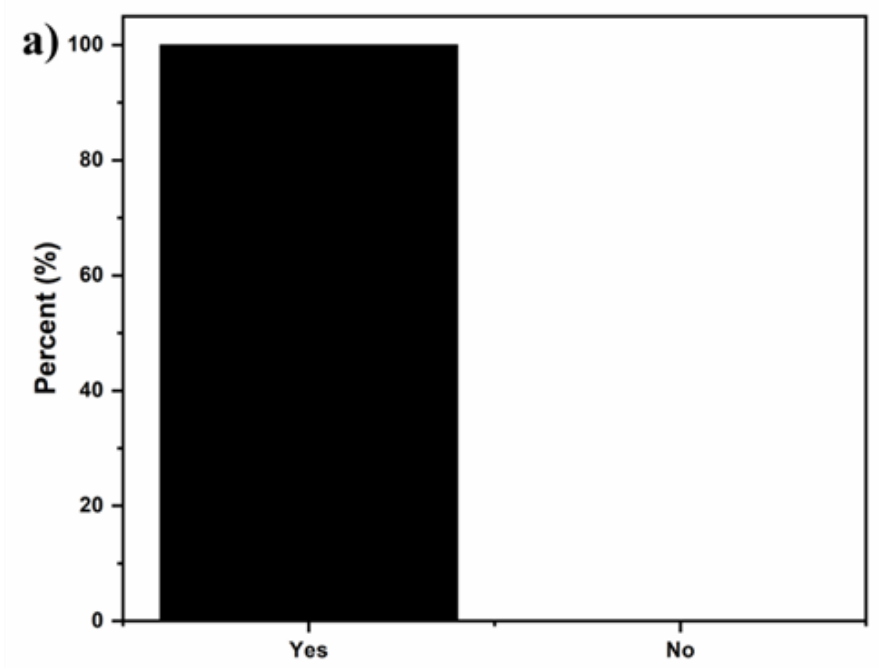

Do you feel the importance of teamwork and collaboration in this project?

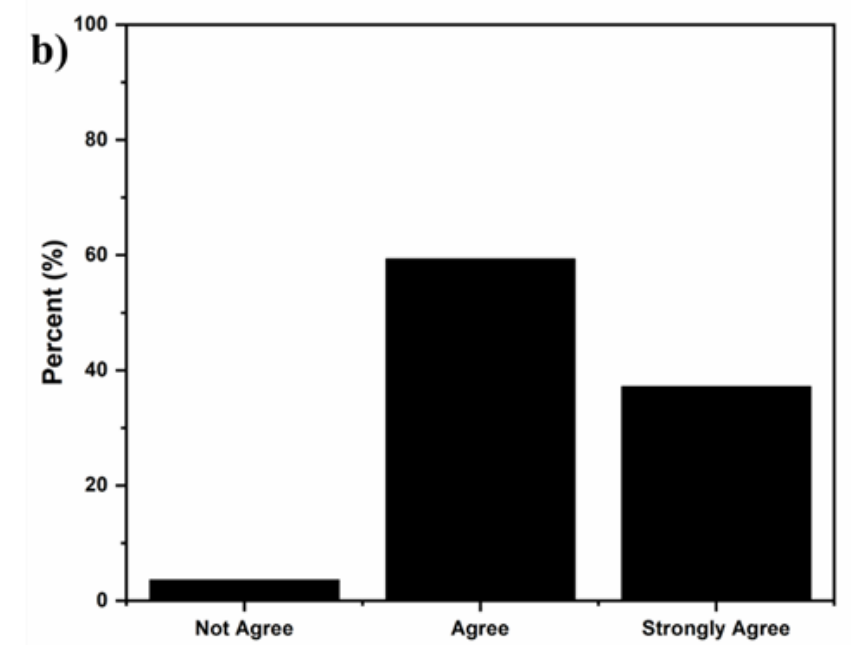

Integrated project saves more time compared to separated projects

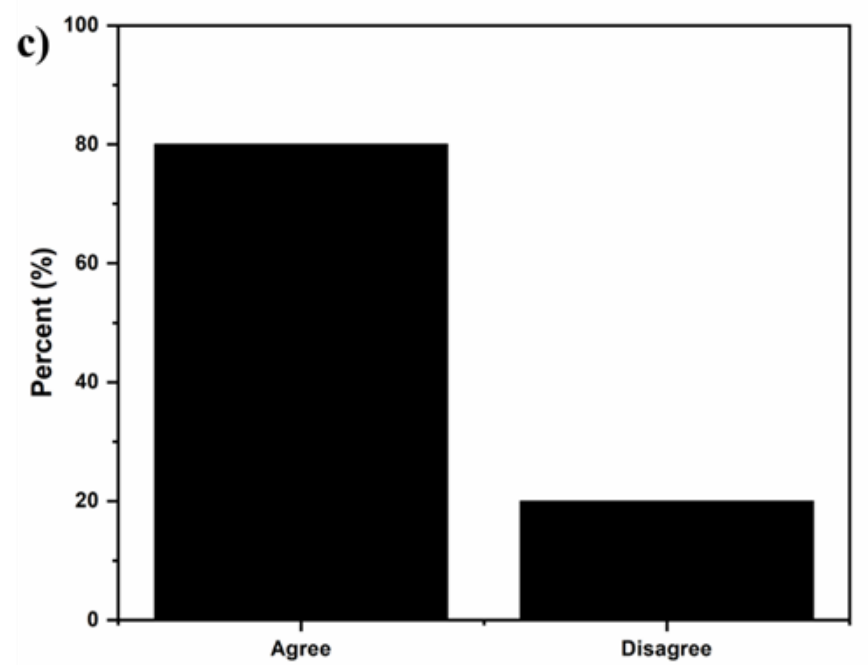

I would like to see this type of integrated project in more of my courses

Figure 5. Feedback of students on a) the importance of teamwork and collaboration, b) the project helps to save time, and c) in favor to get the same type of project in other courses. 


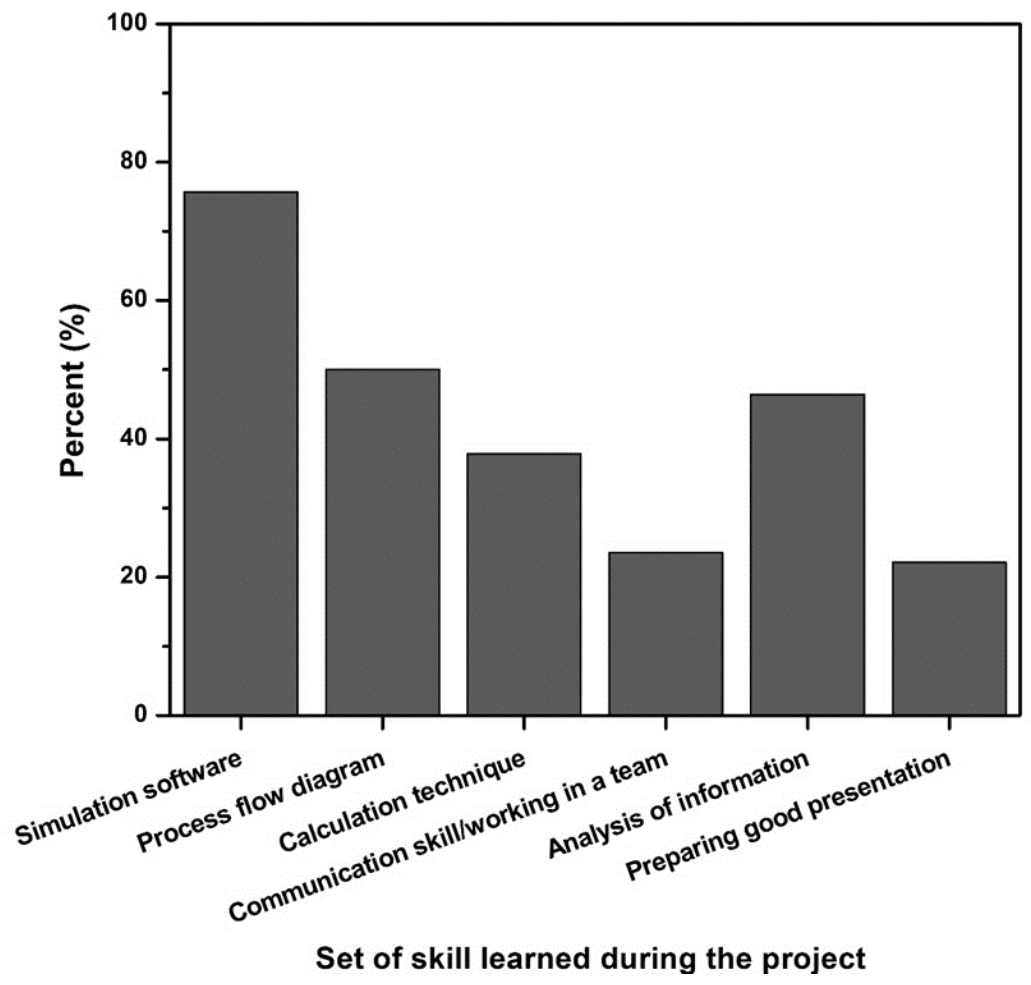

Figure 6. Polling on skills learned during the project.

\section{CONCLUSION}

The integrated project is intended to give experience to students in implementing concepts that they have learned in class upon the real case problems. By using the knowledge that they have and sharing ideas among the team members, they need to come up with the design process shown in the report and present it in a short video. The project can train students to operate important simulation tools for chemical processes and early exposure to drawing a process flow diagram. The acceptance of this type of project has been very positive by the majority of students, and the skills that they learn include simulation software operation, drawing of process flow diagram, calculation technique, communication skills during working in a team, analysis of information, and preparing a good presentation.

\section{ACKNOWLEDGMENTS}

The authors would like to acknowledge students who took the class during September 2020 students for giving good cooperation in responding to the polls/questionnaires.

\section{AUTHORS' NOTE}

The authors declare that there is no conflict of interest regarding the publication of this article. The authors confirmed that the paper was free of plagiarism.

\section{REFERENCES}

Antequera Caplliure, M., and Herrero Montagud, M. (2012). The integrated project as a learning experience. JOTSE: Journal of technology and science education, 2(1), 13-21. 
Ballesteros, M. A., Daza, M. A., Valdés, J. P., Ratkovich, N., and Reyes, L. H. (2019). Applying PBL methodologies to the chemical engineering courses: Unit operations and modeling and simulation, using a joint course project. Education for Chemical Engineers, 27, 35-42.

Baran, M., and Sozbilir, M. (2018). An application of context-and problem-based learning (CPBL) into teaching thermodynamics. Research in Science Education, 48(4), 663-689.

Lopez-Zamora, S., Kong, J., Escobedo, S., and Lasa, H. D. (2021). Thermodynamics and Machine Learning Based Approaches for Vapor-Liquid-Liquid Phase Equilibria in nOctane/Water, as a Naphtha-Water Surrogate in Water Blends. Processes, 9(3), 413.

Mulop, N., Yusof, K. M., and Tasir, Z. (2012). A review on enhancing the teaching and learning of thermodynamics. Procedia-Social and Behavioral Sciences, 56, 703-712.

Sidik, H., and Masek, A. (2021). The Effects of Problem-based Learning in Students Reading Comprehension for Mastering the Content and Vocabulary Acquisition. ASEAN Journal of Science and Engineering Education, 1(2), 87-92.

Trisdiono, H., Siswandari, S., Suryani, N., and Joyoatmojo, S. (2019). Multidisciplinary integrated project-based learning to improve critical thinking skills and collaboration. International Journal of Learning, Teaching and Educational Research, 18(1), 16-30. 